Article type : Reviews

\title{
Corticobasal Syndrome: Neuroimaging and Neurophysiological
}

\section{Advances}

Flavio Di Stasio ${ }^{1^{*}}$, Antonio Suppa ${ }^{1-2^{*}}$, Luca Marsili ${ }^{2}$, Neeraj Upadhyay ${ }^{2}$, Francesco Asci

${ }^{2}$, Matteo Bologna ${ }^{1-2}$, Carlo Colosimo ${ }^{3}$, Giovanni Fabbrini ${ }^{1-2}$, Patrizia Pantano ${ }^{1-2}$, Alfredo Berardelli $^{1-2}$.

${ }^{1}$ IRCCS Neuromed Institute, Pozzilli (IS), ${ }^{2}$ Department of Human Neuroscience,

"Sapienza" University of Rome, Italy, ${ }^{3}$ Department of Neurology, Santa Maria University

Hospital, Terni, Italy

*the authors equally contributed to this work

\section{Corresponding author:}

Alfredo Berardelli, MD

Department of Human Neuroscience, and

IRCCS Neuromed Institute,

This article has been accepted for publication and undergone full peer review but has not been through the copyediting, typesetting, pagination and proofreading process, which may lead to differences between this version and the Version of Record. Please cite this article as doi: 10.1111/ene.13928

This article is protected by copyright. All rights reserved. 
Sapienza University of Rome,

Viale dell’Università, 30, 00185 Rome, Italy

Telephone number: +39-06-49914700

Fax: +39-06-49914700

E-mail: alfredo.berardelli@uniroma1.it

Keywords: corticobasal degeneration; corticobasal syndrome; atypical parkinsonism; neuroimaging; neurophysiology; theta burst stimulation

Running Head: Neuroimaging and neurophysiology in corticobasal syndrome

\begin{abstract}
Corticobasal degeneration (CBD) is a neurodegenerative condition characterized by $4 \mathrm{R}-\mathrm{tau}$ protein deposition in several brain regions that clinically manifests itself as a heterogeneous atypical parkinsonism typically expressing in the adulthood. The prototypical clinical phenotype of CBD is corticobasal syndrome (CBS). Important insights into the pathophysiological mechanisms underlying motor and higher cortical symptoms in CBS have been gained by using advanced neuroimaging and neurophysiological techniques. Structural and functional neuroimaging studies often showed asymmetric cortical and subcortical abnormalities, mainly involving perirolandic and parietal regions and basal ganglia structures. Neurophysiological investigations including electroencephalography and somatosensory evoked potentials provided useful information on the origin of myoclonus and on cortical sensory loss. Transcranial magnetic stimulation demonstrated heterogeneous and asymmetric changes in the excitability and plasticity of primary motor cortex and abnormal hemispheric
\end{abstract}

This article is protected by copyright. All rights reserved. 
connectivity. Neuroimaging and neurophysiological abnormalities in multiple brain areas reflect the asymmetric neurodegeneration, leading to the asymmetric motor and higher cortical symptoms in CBS.

\section{INTRODUCTION}

Corticobasal degeneration (CBD) is considered a rare progressive neurodegenerative disorder with onset in the adulthood, with a fatal prognosis and no effective therapies [1-3]. CBD is characterized by $4 \mathrm{R}$ tau protein deposition in the microtubule-binding domain and, in a minority of patients, by deposition of the microtubule associated protein tau (MAPT) haplotype H1 subtype $c$ [4-7]. Four-R tau protein pathology is also found in other neurodegenerative disorders such as progressive supranuclear palsy (PSP). CBD and PSP, however, differ in histopathological findings and topographic tau-deposition distribution [7, 8]. Whether CBD and PSP should be considered two different phenotypes of the same disorder remains a matter of debate owing to the significant overlap in the clinical features of CBD and PSP [9-11].

Clinically, the prototypical phenotype of CBD is corticobasal syndrome (CBS), which is found in $35-50 \%$ of patients with pathologically confirmed CBD [1, 3]. CBS is characterized by parkinsonism and a combination of asymmetric motor (rigidity, akinesia, dystonia and myoclonus) and higher cortical symptoms mainly of the cognitive-behavioral domain (apraxia, agnosia, cortical sensory loss and alien limb phenomena). Besides CBS, CBD may manifest with other clinical phenotypes such as the frontal behavioral-spatial syndrome (FBS) and the non-fluent/agrammatic variant of primary progressive aphasia (naPPA). Furthermore, CBS may also be the clinical manifestation of other tauopathies, such as PSP, frontotemporal lobar degeneration (FTLD) with parkinsonism linked to chromosome 17, Alzheimer's disease (AD) and posterior cortical atrophy (PCA) [1-3]. The high rate of 
clinical overlapping between these neurodegenerative disorders make the in vivo diagnosis of CBD rather challenging. The specific clinical features manifested by the patients with CBS reflect however, the distribution of the underlying tau-related pathology. Clinico-pathological studies indeed suggested that CBS reflects neurodegenerative processes characterized by prominent perirolandic atrophy $[12,13]$.

Although a number of advances have been made in the definition of the clinical and pathological features of this neurodegenerative condition over the last decade, the pathophysiological mechanisms underlying the motor and higher cortical abnormalities associated with this disease are still unclear. In this review, we report the most relevant neuroimaging and neurophysiological studies performed in patients affected by CBS discussing the most recent advances in the pathophysiology of CBS.

\section{Literature Search and methods}

A literature search was performed using the electronic databases PubMed, Scopus, Cochrane Library and Web of Science using the following key-words: "corticobasal degeneration" or "corticobasal syndrome" and "neuroimaging" or "PET" or "SPECT" or "structural MRI" or "DTI" or "functional MRI" or "resting state MRI". We also used as key-words “corticobasal degeneration" or "corticobasal syndrome" and "neurophysiology" or "transcranial magnetic stimulation" or "movement analysis". In this paper, we have reviewed and discussed neuroimaging and neurophysiological studies which gave the most informative contribution to the issue of pathophysiology of CBS. It is important to note that in the large majority of the studies there was no pathological confirmation of the diagnosis of CBD. Moreover, since validated and uniformly employed diagnostic criteria have been achieved only over recent years [1, 3], the studies performed before 2013 are characterized by a less rigorous terminology (i.e. indiscriminately using terms like CBD and CBS). Accordingly, in this 
review, we will use the term CBS instead of CBD for all neuroimaging and neurophysiological studies not including post mortem diagnosis of CBD.

\section{NEUROIMAGING STUDIES}

During the early 1990s, neuroimaging studies in patients diagnosed with CBS mainly focused on the evidence of asymmetric cerebral glucose hypometabolism and hypoperfusion in the fronto-parietal brain regions, basal ganglia and thalamus detected by means of positron emission tomography (PET) and single photon emission computed tomography (SPECT) techniques [14-17]. More recently, PET and SPECT studies have confirmed that the distribution pattern of decreased glucose metabolism and cerebral blood flow in patients with CBS is asymmetric, with the fronto-parietal cortex and the subcortical structures, such as the caudate and putamen, contralateral to the clinically more affected side being involved to a greater extent [18-21]. Among SPECT techniques, dopamine (DA)-related ligands may be used to assess function at presynaptic (e.g. by means of DA transporter - DAT imaging) as well as postsynaptic binding sites (e.g. by means of D2 receptor imaging) in Parkinson's disease (PD) as well as in atypical parkinsonism including PSP and CBS [22]. Several studies in CBS have demonstrated asymmetric reduction of dopaminergic function in caudate and putamen and an high degree of variability [22, 23-26]. Furthermore, in CBS the presynaptic nigrostriatal function may be preserved in the early stages in neuropathologically confirmed cases $[25,27,28]$, suggesting a decrease in DAT activity developing in the late stages of disease [29]. Similarly, studies using D2 receptor SPECT analysis in CBS showed a variable asymmetric reduction of striatal D2 receptor binding accounting for the lack of response to dopaminergic therapy to motor symptoms in CBS [24, 25, 30, 31].

This article is protected by copyright. All rights reserved. 
PET imaging with [11C] N-methylpiperidin-4-yl acetate, aimed to measure brain acetylcholinesterase activity, demonstrated altered cholinergic transmission in patients with CBS in the paracentral region, frontal, parietal and occipital cortices [32]. Recent [F-18]-AV1451 PET studies in patients with CBD, demonstrated asymmetric increased binding in several brain regions contralateral to the symptomatic body side [33-36]. Another PET study using 18-F-THK5351 reported increased binding retention in brain regions contralateral to the most affected limb [37]. All these reports however, are based on a limited number of CBS patients and not always with a pathological confirmation. Furthermore the limitation of these PET studies is due to the rather limited binding of the tau ligand to straight filament $4 \mathrm{R}$ predominant tau and the off-target binding [38].

Neuroimaging approaches have recently provided new tools to understand the pathophysiological changes underlying CBS through the detection of specific structural and functional biomarkers (Figure 1 and Table 1). Only few and dated studies with conventional MRI techniques have been conducted on CBS patients often reporting asymmetric frontoparietal cortical atrophy contralateral to the more clinically affected side [39-43]. By using voxel-based morphometry (VBM) approaches, some magnetic resonance imaging (MRI) studies, have revealed that CBS is associated with prominent asymmetric atrophy in the fronto-parietal cortex and in the basal ganglia [44-49]. In a previous study by Whitwell et al. [47], CBS patients with a post-mortem diagnosis of CBD displayed focal atrophy of premotor and supplemental motor areas, while CBS patients with a post-mortem diagnosis of FTLD with TDP-43 immunoreactivity had widespread atrophy in the fronto-temporal lobe; CBS patients with a post-mortem diagnosis of AD showed atrophy in the temporo-parietal cortex and precuneus. In this study, all the CBS pathologic groups showed an asymmetric imaging pattern regardless the different brain areas involved [47]. Moreover, Burrell et al. (2014) [50] and Jütten et al. (2014) [51] reported an asymmetric fronto-parietal atrophy contralateral to 
the apraxic limb suggesting unbalanced involvement of cortical atrophy in the pathophysiology of higher cortical symptoms. When Upadhyay et al. (2016) [52] more recently used surface-based morphometry $(\mathrm{SBM})$ in patients with probable-CBS, they reported that reduced cortical thickness $(\mathrm{CTh})$ in the fronto-parietal regions contralateral to the clinically more affected side is a more sensitive measure than volumetric changes. Hence, the distribution of neurodegenerative cortical processes appears to be directly related to the pathophysiology of the asymmetric presentation of motor and higher cortical symptoms in CBS [52]. Furthermore, asymmetric SBM changes in patients with probable-CBS have been reported to decrease as the disease progresses, which suggest that, the neurodegenerative process spreads bilaterally, involving both hemispheres in the advanced stages of the disorder [52]. The complex clinical phenotype observed in the advanced stages of CBS is likely to result from a more widespread pattern of cortical and subcortical areas degeneration. SBM studies have shown that patterns of structural changes in patients with CBS differ from those in patients with PSP. CTh in the peri-rolandic regions was smaller in CBS than in PSP patients, while surface area (SA) was markedly smaller in PSP suggesting a greater intracortical WM loss in this condition than in CBS [53]. Overall, these SBM findings point to different pathophysiological mechanisms in PSP and CBS, which is in keeping with pathological evidence of greater tau protein deposition in subcortical structures, including the brainstem and cerebellum, in PSP patients than in CBD patients [53].

Diffusion tensor imaging (DTI) studies on patients with CBS have revealed WM abnormalities in associative fiber bundles and in the cortico-spinal tract [54-56], in addition to asymmetric abnormalities of the corpus callosum, premotor and prefrontal white matter [57]. These findings point to intra and inter-hemispheric structural disconnection processes possibly contributing to the pathophysiology of motor and higher cortical symptoms in CBS patients. More recently, Upadhyay et al. (2016) found axial diffusivity (AxD) to be more 
affected than radial diffusivity changes (RD) in probable-CBS patients [52, 53]. Giving that, among DTI measures, AxD points to axonal loss, whereas RD changes denotes myelin damage, the authors concluded that WM changes in CBS patients reflect prominent axonal damage rather than demyelination $[52,53]$. A recent longitudinal study reported DTI changes around the central sulci and in the superior fronto-occipital fasciculus over a 6 month followup period suggesting that DTI measures might help to follow the pathological progression in patients with CBS [56]. Further noteworthy information has come from DTI studies comparing patients with CBS and PSP. Whitwell et al. (2014) [56] showed that patients with CBS had a more supratentorial, posterior and asymmetric pattern of DTI abnormalities with greater involvement of the splenium of the corpus callosum, premotor, motor and parietal lobes than patients with PSP. Conversely, PSP showed a more symmetric and infratentorial pattern of degeneration, with greater involvement of the superior cerebellar peduncles and midbrain than CBS [56]. Upadhyay et al. (2016) [53] found marked alterations in AxD in CBS, suggesting a prominent axonal loss, as opposed to increased RD and unaltered AxD in patients with PSP suggesting greater degree of myelin than axonal damage.

Besides structural MRI findings, several authors have investigated possible functional connectivity (FC) changes in patients with CBS using resting-state functional MRI (rs-fMRI) [58-60]. Bharti et al. (2017) [59] showed that patients with CBS had increased withinnetwork FC than healthy subjects in the default mode, cerebellum, sensorimotor, executivecontrol and insular networks suggesting global intrinsic hyperconnectivity among brain regions deputed to motor and cognitive/affective functions. Increased FC has been interpreted as a plasticity-related shift in neuronal activity from atrophic to intact brain structures or as a direct consequence of disrupted neuronal activity caused by neurodegeneration [59]. Upadhyay et al. (2017) [60] found an increased FC between the dentate nucleus and the sensorimotor cortices, mainly contralateral to the most clinically affected body side,

This article is protected by copyright. All rights reserved. 
suggesting an unbalanced reorganization of the cerebellum connections secondary to asymmetric motor and higher cortical symptoms. Again Ukmar et al. [58] reported the reduced activation of the motor areas and parietal lobe contralateral to the more affected arm during a simple and complex motor task. Furthermore, fMRI studies have disclosed marked differences in FC between patients with CBS and those with PSP. Functional disconnection of the thalamus with various cortical and cerebellar areas was evident in both syndromes, while FC of the dentate nucleus decreased in subcortical and prefrontal cortical areas in PSP, but increased asymmetrically in the frontal cortex in CBS $[59,60]$.

To sum up, molecular and structural neuroimaging studies have suggested the pathophysiological role in patients with CBS for asymmetric abnormalities in the premotor, motor and parietal cortical areas in addition to neurodegeneration in subcortical structures including basal ganglia and corpus callosum. As the disease progresses, multiple brain areas are involved and both hemispheres are affected in the late stages of CBS. Furthermore, functional neuroimaging studies have proved a functional involvement of multiple inter and intra-hemispheric brain connections including cerebellum, sensory-motor and insular networks.

\section{NEUROPHYSIOLOGICAL STUDIES}

Observations from neurophysiological studies on patients with CBS are prevalently based on a limited number of participants. As shown in Figure 2 and Table 2, the majority of neurophysiological studies on CBS patients have been designed to explore single motor (e.g. myoclonus) or higher cortical symptoms (e.g. apraxia) and have rarely adopted standardized clinical criteria for the diagnosis of CBS. Early neurophysiological studies on CBS suggested that apraxia might reflect the altered integration of somatosensory afferent inputs in the fronto-parietal cortices, which would in turn lead to cortical sensory loss or alien limb

This article is protected by copyright. All rights reserved. 
phenomena, two higher cortical symptoms observed in CBS [61-66]. Leiguarda et al. [67] analyzed the kinematic features of apraxic movements reporting delayed initiation of the movement and slowed, distorted and fragmented finger movements of the affected hand. Furthermore, Okuda et al. (1998) [68] hypothesized that the prolonged somatosensory evoked potential (SEP)' N20 component latency plays a role in the pathophysiology of cortical sensory loss and apraxia. Another typical symptom in CBS is myoclonus, which is usually characterized by a pattern of a synchronous, short-lasting EMG bursts recorded from agonist and antagonist muscles. CBS may also manifest itself through action myoclonus usually associated with a dystonic posture $[69,70]$. These neurophysiological patterns of myoclonus observed in CBS appear to be different from those observed in other complex syndromes associated with parkinsonism, such as multiple system atrophy $[69,70]$. Furthermore, the lack of associated large EEG potentials or giant SEPs and the shorter latency of myoclonus in CBS than that observed in the classical stimulus-sensitive myoclonus lend further support to the existence of a subcortical network underlying myoclonus in CBS [69, 70].

The neurophysiological tools currently available include transcranial magnetic stimulation (TMS), which has been increasingly used to investigate the primary motor cortex (M1) excitability and functional connectivity between brain areas [72,73]. Previous TMS studies on CBS reported an increased resting motor threshold (RMT) and flattened input/output (I/O) curve, thus pointing to a reduced M1 excitability in this disorder [73]. The observation that the cortical silent period (cSP) is also shortened in patients with CBS is indicative of a deficit in GABA-ergic inhibition in M1. In addition, by using single-pulse TMS to elicit the ipsilateral silent period (iSP), which reflects the activation of interhemispheric connections, Trompetto et al. (2003) [65] found a reduced iSP suggesting reduced transcallosal inhibition in CBS. Paired-pulse TMS protocols revealed reduced shortinterval intracortical inhibition (SICI) in patients with CBS, which again demonstrates 
reduced GABA-ergic inhibition in M1 [61-64, 66]. Interestingly, there was a significant correlation between the amount of SICI and the degree of M1 atrophy as measured by VBM, which points to a pathophysiological role of M1 atrophy in the genesis of motor and higher cortical symptoms in CBS [74].

More advanced repetitive TMS techniques, such as theta-burst stimulation (TBS), have more recently been used to study mechanisms of synaptic plasticity in M1 in patients with CBS [75-78]. In humans, synaptic plasticity can be assessed in M1 by measuring longterm changes in motor evoked potentials (MEPs) amplitude following repetitive stimulation of M1 with plasticity-inducing protocols. In particular, intermittent-TBS elicits mechanisms of long-term potentiation (LTP)-like plasticity, whereas continuous-TBS induces mechanisms of long-term depression (LTD)-like plasticity [75-78]. LTP and LTD-like plasticity are physiological mechanisms that have been widely acknowledged to underlie motor execution and learning. Investigating M1 plasticity is an issue of considerable scientific relevance to better interpret the pathophysiology of motor symptoms in neurodegenerative disorders including CBS [75-79].

In a relatively large cohort of patients with probable-CBS, TBS disclosed heterogeneous features [76]. In one subgroup of these patients, MEPs were virtually unrecordable and typically polyphasic in shape, even at the maximum stimulator output. This suggests that the cortico-spinal tract is involved in widespread cortical degeneration, which may be a consequence of a more advanced disease and lead to a de-efferentation process [74, 76, 80]. The study also revealed asymmetric responses in terms of LTP- and LTD-like plasticity when the M1 contralateral to the clinically less affected side (manifesting parkinsonism) was compared with that on the clinically more affected side (manifesting dystonia, apraxia, alien limb phenomena and cortical sensory deficit) [76]. This heterogeneous neurophysiological response to TBS seems to be specific to CBS and is in This article is protected by copyright. All rights reserved. 
contrast to the response reported in PSP, which is characterized by enhanced M1 LTP-like plasticity $[76,79,81]$. Within this context, the different responses to TBS-induced LTP/LTDlike plasticity in patients with PSP and CBS suggest that the underlying pathophysiological mechanisms in these two conditions are different $[76,79]$.

In summary, prolonged SEPs observed in CBS patients may reflect somatosensory cortex abnormalities causing apraxia and cortical sensory loss. Myoclonus in CBS is characterized by the absence of abnormal EEG potentials and giant SEPs and by a short onset latency suggesting the involvement of subcortical structures. MEPs after M1 stimulation in some patients are asymmetric or even absent implying an asymmetric impairment of the cortical-spinal tract. Furthermore, TMS studies have demonstrated altered M1 excitability, reduced intracortical and inter-hemispheric inhibition and abnormal integration of somatosensory afferent inputs in the motor and sensory cortices. The abnormal and often asymmetric M1 plasticity found in CBS patients also suggests abnormal motor inputs from non-primary motor and non-motor areas or from the basal ganglia.

\section{DISCUSSION}

Recent neuroimaging studies demonstrated a number of structural, functional and metabolic abnormalities leading to a better understanding of pathophysiological mechanisms contributing to specific symptoms and signs in patients with CBS. Structural studies have demonstrated that asymmetric degeneration in fronto-parietal cortex is likely responsible for unilateral symptoms such as alien limb phenomena, cortical sensory loss and apraxia in CBS. Furthermore, neurodegeneration of subcortical brain areas, particularly the basal ganglia, and intra- and inter-hemispheric structural disconnection processes are likely to be involved in motor symptoms such as dystonia, myoclonus and parkinsonian features. Asymmetric DTI abnormalities in several associative fiber bundles and in the cortico-spinal tract may also

This article is protected by copyright. All rights reserved. 
contribute to specific CBS features. As the disease progresses, additional cortical and subcortical brain areas become part of a wider neurodegenerative process that results in the heterogeneous and complex clinical phenotype that is typical of the late stage of CBS. In addition to structural abnormalities, SPECT and PET studies found asymmetric metabolic changes possibly contributing to parkinsonism and other asymmetric motor signs and symptoms in CBS. Asymmetric functional reorganization in cortical and sub-cortical structures likely plays an important role in the pathophysiology of CBS. Altered FC in cerebellum, thalamus, and sensorimotor cortex possibly reflects a global intrinsic hyperconnectivity among brain networks compensatory to asymmetric motor and higher cortical symptoms. Recent neurophysiological studies have also led to a better understanding of the asymmetric neurophysiological abnormalities in specific brain networks in patients with CBS by shedding light on the correlation between altered neurophysiological mechanisms and asymmetric clinical symptoms. It is reasonable to assume that abnormal M1 excitability and LTP/LTD-like plasticity play a crucial role not only in rigidity and bradykinesia but also in focal motor symptoms such as dystonia, thereby reflecting the structural and functional impairment of cortico-basal ganglia-thalamo-cortical motor loops. By contrast, asymmetric higher cortical symptoms, such as apraxia, cortical sensory loss and alien limb phenomena, are likely to reflect a more complex neurophysiological model that results in a corticocortical disconnection syndrome due to the altered integration of somatosensory afferent inputs in the motor and sensory cortices. Asymmetric neurophysiological measures might help in differentiating CBD/CBS from other clinical presentations of CBD (e.g. PSP-S) [82, 83]. Hence, structural and functional neuroimaging and neurophysiological studies on CBS have clearly revealed a degree of asymmetry in a number of structural and functional measures that highlights the imbalance in the severity of the neurodegenerative processes in the two hemispheres. This imbalance in turn leads to the typical asymmetric CBS phenotype 
characterized by prominent motor and higher cortical symptoms involving the limb contralateral to the more affected hemisphere. It is important to underline that although CBS diagnosis is supported by the presence of asymmetric clinical and neuroimaging features, a clinico-pathological study reported a post-mortem diagnosis of CBD in patients with symmetric clinical motor symptoms and symmetric structural and functional neuroimaging abnormalities [82].

One important pathophysiological issue in CBS that has yet to be explained concerns the etiopathogenetic mechanisms underlying the asymmetric degeneration and, consequently, the asymmetric presentation of the motor and higher cortical symptoms. One clinical study on a small cohort of patients with CBS reported that arm dystonia, a common motor symptom of the CBS spectrum, is more often observed on the contralateral side of the dominant hand [84]. Considering the disproportionate use of the dominant arm for a range motor tasks, it has been speculated that the non-dominant hemisphere may be more susceptible to neurodegenerative processes owing to a difference in the "strength" of the neuronal networks between that hemisphere and the dominant hemisphere [84]. Whether the asymmetric neuronal degeneration in CBD starts from an involvement of more vulnerable areas or not is however still unclear. One explanation might be that the asymmetry in macroscopic grey matter atrophy and white matter degeneration in $\mathrm{CBD}$ reflects the asymmetry in microscopic tau protein deposition. This hypothesis is supported by histopathological studies on patients with post-mortem diagnosis of CBD that have disclosed an asymmetric aggregation of tau protein, with a greater aggregation in the hemisphere contralateral to the more affected body side [85]. The pathophysiological mechanisms underlying asymmetric tau protein deposition in CBD are far from clear. Boluda et al. (2015) [86] suggested that different types of tau induce a wide spectrum of brain pathologies that point to new models of self-propagating tau protein transmission through different interconnected neuroanatomical pathways. Although

This article is protected by copyright. All rights reserved. 
this hypothesis is supported by a presumed pathophysiological link between the abnormal post-transcriptional phosphorylation of tau-protein and a range of cortical and subcortical dissemination patterns in tauopathies [86], the enigmatic pattern of distribution of tau pathology in CBD warrants further studies.

In conclusion, this review focuses on neuroimaging and neurophysiological findings in CBS highlighting the important advances that have recently been made in our understanding of this disease and that point to asymmetry as a relevant feature of CBS. Indeed, recent neuroimaging and neurophysiological studies have shed light on the pathophysiological bases of asymmetric motor and higher cortical symptoms in patients with CBS. However, it should be taken into account that neurodegenerative disorders other than CBD may manifest with asymmetric clinical as well as neuroimaging features (e.g. FTLD, PSP, AD and PCA) and that CBD may manifest with symmetric clinical and neuroimaging features [82]. Furthermore, it is important to clarify that in the absence of a pathological confirmation of CBD in the large majority of neuroimaging and neurophysiological studies here reported, the observed findings should be interpreted and referred to the clinical phenotype of CBS rather than CBD. Moreover, owing to the well-known clinical heterogeneity of CBS, future studies on larger cohorts of patients clustered in homogeneous phenotypes and with pathological confirmation of CBD are required to reduce the overall current variability of neuroimaging and neurophysiological measures. Further multidisciplinary studies designed to combine neuroimaging and neurophysiological techniques will help to improve the in vivo diagnosis of $\mathrm{CBD}$, which is crucial to design targeted therapies aimed at slowing down the pathological progression of this disease [87].

\section{DISCLOSURE OF CONFLICTS OF INTEREST}

The authors declare no financial or other conflicts of interest.

This article is protected by copyright. All rights reserved. 


\section{REFERENCES}

1. Alexander SK, Rittman T, Xuereb JH, Bak TH, Hodges JR, Rowe JB. Validation of the new consensus criteria for the diagnosis of corticobasal degeneration. J Neurol Neurosurg Psychiatry 2014; 85: 923-927.

2. Ali F, Josephs KA. Corticobasal degeneration: key emerging issues. J Neurol 2018; 265: 439-435.

3. Armstrong MJ, Litvan I, Lang AE, et al. Criteria for the diagnosis of corticobasal degeneration. Neurology 2013; 80: 496-503.

4. Pittman AM, Myers AJ, Abou-Sleiman P, et al. Linkage disequilibrium fine mapping and haplotype association analysis of the tau gene in progressive supranuclear palsy and corticobasal degeneration. J Med Genet 2005; 42: 837-846.

5. Boeve BF, Josephs KA, Drubach DA. Current and future management of the corticobasal syndrome and corticobasal degeneration. Handb Clin Neurol 2008; 89: 533-548.

6. Dickson D, Bergeron C, Chin S, et al. Office of Rare Diseases neuropathologic criteria for corticobasal degeneration. J Neuropathol Exp Neurol 2002; 61: 935-946.

7. Kouri N, Whitwell JL, Josephs KA, Rademakers R, Dickson DW. Corticobasal degeneration: a pathologically distinct 4R tauopathy. Nat Rev Neurol 2011; 7: 263-272.

8. Josephs KA. Key emerging issues in progressive supranuclear palsy and corticobasal degeneration. J Neurol 2015; 262: 783-788.

9. Höglinger G. Is it Useful to Classify Progressive Supranuclear Palsy and Corticobasal Degeneration as Different Disorders? No. Movement Disorders Clinical Practice 2018; doi: $10.1002 / \mathrm{mdc} 3.12582$.

10. Ling H, Macerollo A. Is it Useful to Classify PSP and CBD as Different Disorders? Yes. Movement Disorders Clinical Practice 2018; doi: 10.1002/mdc3.12581.

This article is protected by copyright. All rights reserved. 
11. Ling H, O'Sullivan SS, Holton JL et al. Does corticobasal degeneration exist? A clinicopathological re-evaluation. Brain 2010; 133: 2045-2057.

12. Irwin DJ. Tauopathies as clinicopathological entities. Parkinsonism Relat Disord 2016; 22: S29-S33.

13. Lee SE, Rabinovici GD, Mayo MC et al. Clinicopathological correlations in corticobasal degeneration. Ann Neurol 2011; 70: 327-340.

14. Blin J, Vidailhet M, Pillon B, Dubois B, Feve JR, Agid Y. Corticobasal degeneration: decreased and asymmetrical glucose consumption as studied with PET. Mov Disord 1992; 7: 348-354.

15. Eidelberg D, Dhawan V, Moeller JR, et al. The metabolic landscape of corticobasal ganglionic degeneration: regional asymmetries studied with positron emission tomography. J Neurol Neurosurg Psychiatry 1991; 54: 787-792.

16. Markus HS, Lees AJ, Lennox G, Marsden CD, Costa DC. Patterns of cerebral blood flow in corticobasal degeneration studied using HMPAO SPECT; comparison with Parkinson's disease and normal controls. Mov Disord 1995; 10: 179-187.

17. Nagasawa H, Tanji H, Nomura H, et al. PET study of cerebral glucose metabolism and fluorodopa uptake in patients with corticobasal degeneration. J Neurol Sci 1996: 139: 210-217.

18. Abe Y, Kimura N, Goto M, Aso Y, Matsubara E. Brain Perfusion in Corticobasal Syndrome with Progressive Aphasia. Dement Geriatr Cogn Dis Extra 2016; 6: 133-141.

19. Niethammer M, Tang CC, Feigin A, et al. A disease-specific metabolic brain network associated with corticobasal degeneration. Brain 2014; 137: 3036-3046.

20. Sławek J Lass P, Derejko M, Dubaniewicz M. Cerebral blood fow SPECT may be helpful in establishing the diagnosis of progressive supranuclear palsy and corticobasal degeneration. Nucl Med Rev Cent East Eur 2001; 4:73-76.

This article is protected by copyright. All rights reserved. 
21. Turaga, SP, Mridula R, Borgohain R. Cerebral glucose metabolism, clinical, neuropsychological, and radiological profile in patients with corticobasal syndrome. Neurol India 2013; 61: 7-11.

22. Booth TC, Nathan M, Waldman AD, Quigley AM, Schapira AH, Buscombe J. The role of functional dopamine-transporter SPECT imaging in parkinsonian syndromes, part 2. AJNR Am J Neuroradiol 2015; 36: 236-244.

23. Cilia R, Rossi C, Frosini D, et al. Dopamine transporter SPECT imaging in corticobasal syndrome. PLoS One 2011; 6: e18301.

24. Hammesfahr S, Antke C, Mamlins E, et al. IBZM-SPECT in Corticobasal Syndrome: Results from a Clinical Follow-Up Study. Neurodegener Dis 2016; 16: 342-347.

25. Klaffke S, Kuhn AA, Plotkin M, et al. Dopamine transporters, D2 receptors, and glucose metabolism in corticobasal degeneration. Mov Disord 2006; 21: 1724-1727.

26. Plotkin M, Amthauer H, Klaffke S, et al. Combined 123I-FP-CIT and 123I-IBZM SPECT for the diagnosis of parkinsonian syndromes: study on 72 patients. J Neural Transm (Vienna) 2005; 112:677-692.

27. Kaasinen V, Gardberg M, Roytta M, Seppanen M, Paivarinta M. Normal dopamine transporter SPECT in neuropathologically confirmed corticobasal degeneration. J Neurol 2013; 260: 1410e1.

28. O'Sullivan SS, Burn DJ, Holton JL, Lees AJ. Normal dopamine transporter single photonemisn CT scan in corticobasal degeneration. Mov Disord 2008; 23: 2424e6.

29. R. Ceravolo, C. Rossi, R. Cilia, et al. Evidence of delayed nigrostriatal dysfunction in corticobasal syndrome: a SPECT follow-up study. Parkinsonism Relat Disord 2013; 19: 557-559.

This article is protected by copyright. All rights reserved. 
30. Frisoni GB, Pizzolato G, Zanetti O, Bianchetti A, Chierichetti F, Trabucchi M. Corticobasal degeneration: neuropsychological assessment and dopamine D2 receptor SPECT analysis. Eur Neurol 1995; 1: 50-54.

31. Pirker S, Perju-Dumbrava L, Kovacs GG, et al. Dopamine D2 receptor SPECT in corticobasal syndrome and autopsy-confirmed corticobasal degeneration. Parkinsonism Relat Disord 2013; 19: 222-226.

32. Hirano S, Shinotoh H, Shimada H, et al. Cholinergic imaging in corticobasal syndrome, progressive supranuclear palsy and frontotemporal dementia. Brain J Neurol 2010; 133: 2058-2068.

33. Cho H, Baek MS, Choi JY et al. 18F-AV-1451 binds to motor-related subcortical gray and white matter in corticobasal syndrome. Neurology 2017; 89: 1170-1178.

34. Josephs KA, Whitwell JL, Tacik P, et al. [18F]AV-1451 tau-PET uptake does correlate with quantitatively measured 4R-tau burden in autopsy-confirmed corticobasal degeneration. Acta Neuropathol 2016; 132: 931-933.

35. McMillan CT, Irwin DJ, Nasrallah I et al. Multimodal evaluation demonstrates in vivo 18F-AV-1451 uptake in autopsy-confrmed corticobasal degeneration. Acta Neuropathol 2016; 132: 935-937.

36. Smith R, Schöll M, Widner H et al. In vivo retention of 18F-AV-1451 in corticobasal syndrome. Neurology 2017; 89: 845-853.

37. Kikuchi A, Okamura N, Hasegawa T et al. In vivo visualization of tau deposits in corticobasal syndrome by 18FTHK5351 PET. Neurology 2016; 87: 2309-2316.

38. Villemagne VL, Fodero-Tavoletti MT, Masters CL, Rowe CC. Tau imaging: early progress and future directions. Lancet Neurol 2015; 14: 114-124.

39. Grisoli M, Fetoni, V, Savoiardo M, Girotti F, Bruzzone MG. MRI in corticobasal de generation. Eur J Neurol 1995; 2: 547-552.

This article is protected by copyright. All rights reserved. 
40. Hauser RA, Murtaugh FR, Akhter K, Gold M, Olanow C. Magnetic resonance imaging of corticobasal degeneration. J Neuroimaging 1996; 6: 222-226.

41. Josephs KA, Tang-Wai DF, Edland SD, et al. Correlation between antemortem magnetic resonance imaging findings and pathologically confirmed corticobasal degeneration. Arch Neurol 2004; 61: 1881-1884.

42. Soliveri P, Monza D, Paridi D, et al. Cognitive and magnetic resonance imaging aspects of corticobasal degeneration and progressive supranuclear palsy. Neurology 1999; 53: $502-507$

43. Savoiardo M. Differential diagnosis of Parkinson's disease and atypical parkinsonian disorders by magnetic resonance imaging. Neurol Sci 2003; 24: S35-37.

44. Gröschel K, Hauser TK, Luft A, et al. Magnetic resonance imaging-based volumetry differentiates progressive supranuclear palsy from corticobasal degeneration. Neuroimage 2004; $21: 714-724$.

45. Boxer AL, Geschwind MD, Belfor N, et al. Patterns of brain atrophy that differentiate corticobasal degeneration syndrome from progressive supranuclear palsy. Arch Neurol 2006; 63: 81-86.

46. Josephs KA, Whitwell JL, Dickson DW, et al. Voxel-based morphometry in autopsy proven PSP and CBD. Neurobiol Aging 2008; 29: 280-289.

47. Whitwell JL, Jack Jr CR, Boeve BF, et al. Imaging correlates of pathology in corticobasal syndrome. Neurology 2010; 23: 1279-1287.

48. Yu F, Barron DS, Tantiwongkosi B, Fox P. Patterns of gray matter atrophy in atipical parkinsonism syndromes: a VBM meta-analysis. Brain Behav 2015; 5: e00329.

49. Seppi K, Poewe. Brain magnetic resonance imaging techniques in the diagnosis of parkinsonian syndromes. W Neuroimaging Clin N Am 2010; 1:29-55.

This article is protected by copyright. All rights reserved. 
50. Burrell JR, Hornberger M, Vucic S, Kiernan MC, Hodges JR. Apraxia and motor dysfunction in corticobasal syndrome. PLoS One 2014; 9: e92944.

51. Jütten K, Pieperhoff P, Südmeyer M, et al. Neuropsychological and brain volume differences in patients with left- and right-beginning corticobasal syndrome. PLoS One 2014; 9: e110326.

52. Upadhyay N, Suppa A, Piattella MC, et al. Gray and white matter structural changes in corticobasal syndrome. Neurobiol Aging 2016; 37: 82-90.

53. Upadhyay N, Suppa A, Piattella MC, et al. MRI gray and white matter measures in progressive supranuclear palsy and corticobasal syndrome. J Neurol 2016; 263: 20222031.

54. Borroni B, Garibotto V, Agosti C, et al. White matter changes in corticobasal degeneration syndrome and correlation with limb apraxia. Arch. Neurol 2008; 65: 796801.

55. Tovar-Moll F, de Oliveira-Souza R, Bramati IE, et al. White matter tract damage in the behavioral variant of frontotemporal and corticobasal dementia syndromes. PloS One 2014; 9: e102656.

56. Whitwell JL, Schwarz CG, Reid RI, Kantarci K, Jack CR Jr, Josephs KA. Diffusion tensor imaging comparison of progressive supranuclear palsy and corticobasal syndromes. Parkinsonism Relat Disord 2014; 20: 493-498.

57. Zhang Y, Walter R, Ng P, et al. Progression of Microstructural Degeneration in Progressive Supranuclear Palsy and Corticobasal Syndrome: A Longitudinal Diffusion Tensor Imaging Study. PLoS One 2016; 11: e0157218.

58. Ukmar M, Moretti R, Torre P, Antonello RM, Longo R, Bava A. Corticobasal degeneration: structural and functional MRI and single-photon emission computed tomography. Neuroradiology 2003; 45: 708-712.

This article is protected by copyright. All rights reserved. 
59. Bharti K, Bologna M, Upadhyay N, et al. Abnormal Resting-State Functional Connectivity in Progressive Supranuclear Palsy and Corticobasal Syndrome. Front Neurol 2017; 8: 248.

60. Upadhyay N, Suppa A, Piattella MC, et al. Functional Disconnection of Thalamic and Cerebellar Dentate Nucleus Networks in Progressive Supranuclear Palsy and Corticobasal Syndrome. Parkinsonism Relat Disord 2017; 39: 52-57.

61. Hanajima R, Ugawa Y, Terao Y, Ogata K, Kanazawa I. Ipsilateral cortico-cortical inhibition of the motor cortex in various neurological disorders. J Neurol Sci 1996; 140: 109-116.

62. Lu CS, Ikeda A, Terada K, et al. Electrophysiological studies of early stage corticobasal degeneration. Mov Disord 1998; 13: 140-146.

63. Okuma Y, Urabe T, Mochizuki H, et al. Asymmetric cortico-cortical inhibition in patients with progressive limb-kinetic apraxia. Acta Neurol Scand 2000; 102: 244-248.

64. Pal PK, Gunraj CA, Li JY, Lang AE, Chen, R. Reduced intracortical and interhemispheric inhibitions in corticobasal syndrome J Clin Neurophysiol 2008; 25: 304312.

65. Trompetto C, Buccolieri A, Marchese R, Marinelli L, Michelozzi G, Abbruzzese G. Impairment of transcallosal inhibition in patients with corticobasal degeneration. Clin. Neurophysiol 2003; 114: 2181-2187.

66. Valls-Solé J, Tolosa E, Marti MJ, et al. Examination of motor output pathways in patients with corticobasal ganglionic degeneration using transcranial magnetic stimulation. Brain 2001; 124: 1131-1137.

67. Leiguarda RC, Merello M, Nouzeilles MI, Balej J, Rivero A, Nogués M. Limb-kinetic apraxia in corticobasal degeneration: clinical and kinematic features. Mov Disord 2003; 18: 49-59.

This article is protected by copyright. All rights reserved. 
68. Okuda B, Tachibana H, Takeda M, Kawabata K, Sugita M. Asymmetric changes in somatosensory evoken potentials correlate with limb apraxia in corticobasal degeneration. Acta Neurol Scand 1998; 97: 409-412.

69. Shibasaki H, Hallett M. Electrophysiological studies of myoclonus. Muscle Nerve 2005; 31: $157-174$.

70. Brunt ER, van Weerden TW, Pruim J, Lakke JW. Unique myoclonic pattern in corticobasal degeneration. Mov Disord 1995; 10: 132-142

71. Hallett M. Transcranial magnetic stimulation: a primer. Neuron 2007; 55: 187-199.

72. Berardelli A, Abbruzzese G, Chen R, et al. Consensus paper on short-interval intracortical inhibition and other transcranial magnetic stimulation intracortical paradigms in movement disorders. Brain Stimul 2008; 3:183-191.

73. Kühn AA, Grosse P, Holtz K, Brown P, Meyer BU, Kupsch A. Patterns of abnormal motor cortex excitability in atypical parkinsonian syndromes. Clin Neurophysiol 2004; 115: 1786-1795.

74. Burrell JR, Hodges JR, Rowe JB. Cognition in Corticobasal Syndrome and Progressive Supranuclear Palsy: A Review. Mov Disord 2014; 29: 684-693.

75. Huang YZ, Edwards MJ, Rounis E, Bhatia KP, Rothwell JC. Theta burst stimulation of the human motor cortex. Neuron 2005; 45: 201-206.

76. Suppa A, Di Stasio F, Marsili L, et al. Primary Motor Cortex LTP/LTD-like Plasticity in Probable Cortico-basal Syndrome. J Neurophysiol 2016; 115: 717-727.

77. Suppa A, Huang YZ, Funke K, et al. Ten Years of Theta Burst Stimulation in Humans: Established Knowledge, Unknowns and Prospects. Brain Stimul 2016; 9: 323-335.

78. Huang YZ, Lu MK, Antal A, et al. Plasticity induced by non-invasive transcranial brain stimulation: A position paper. Clin Neurophysiol 2017; 128: 2318-2329.

This article is protected by copyright. All rights reserved. 
79. Bologna M, Suppa A, Di Stasio F, Conte A, Fabbrini G, Berardelli A. Neurophysiological studies on atypical parkinsonian syndromes. Parkinsonism Relat Disord 2017;. 42: 12-21.

80. Tsuchiya K, Murayama S, Mitani K, et al. Constant and severe involvement of Betz cells in corticobasal degeneration is not consistent with pyramidal signs: a clinicopathological study of ten autopsy cases. H Acta Neuropathol 2005; 109: 353-66.

81. Conte A, Belvisi D, Bologna M, et al. Abnormal cortical synaptic plasticity in primary motor area in progressive supranuclear palsy. Cereb. Cortex 2012; 22: 693-700.

82. Hassan A, Whitwell JL, Boeve BF, et al. Symmetric corticobasal degeneration (S-CBD). Parkinsonism Relat Disord 2010; 16: 208-214.

83. Murray ME, Kouri N, Lin WL, Jack CR Jr, Dickson DW, Vemuri P. Clinicopathologic assessment and imaging of tauopathies in neurodegenerative dementias. Alzheimers Res Ther $2014 ; 2: 1$.

84. Rana AQ, Ansari H, Siddiqui I. The relationship between arm dystonia in corticobasal degeneration and handedness. J Clin Neurosci 2012; 19: 1134-1136.

85. Forman MS, Zhukareva V, Bergeron C, et al. Signature tau neuropathology in gray and white matter of corticobasal degeneration. Am J Pathol 2002; 160: 2045-2053.

86. Boluda S, Iba M, Zhang B, Raible KM, Lee VM, Trojanowski JQ. Differential induction and spread of tau pathology in young PS19 tau transgenic mice following intracerebral injections of pathological tau from Alzheimer's disease or corticobasal degeneration brains. Acta Neuropathol 2015; 129: 221-237.

87. Marsili L, Suppa A, Berardelli A, Colosimo C. Therapeutic interventions in parkinsonism: Corticobasal degeneration. Parkinsonism Relat. Disord 2016; 22: S96-100.

This article is protected by copyright. All rights reserved. 


\section{FIGURE LEGENDS}

Figure 1. Main neuroimaging findings reported in corticobasal degeneration and corticobasal syndrome studies. MRI: magnetic resonance imaging; VBM: voxel-based morphometry; SBM: surface-based morphometry; DTI: diffusion tensor imaging; RS-FMRI: resting-state functional-MRI; PET: positron emission tomography; [18F]FDG-PET: [(18)F]6fluorodeoxyglucose-PET; CBF: cerebral blood flow; SPECT: single photon emission computed tomography; FP-CIT-SPECT: ioflupane-SPECT; WM: white matter; CTh: cortical thickness; AxD, axial diffusivity; RD: radial diffusivity.

Figure 2. Main neurophysiological findings reported in corticobasal syndrome studies. SEPs: somatosensory evoked potentials; EMG: electromiography; MA: movement analysis; TMS: transcranial magnetic stimulation; rTMS: repetitive TMS; TBS: theta burst stimulation; M1: primary motor cortex; GABA: gamma-aminobutyric acid; SICI: short-interval intracortical inhibition; ICF: intracortical facilitation; LTD: long-term depression; LTP: long-term potentiation.

\section{TABLE LEGENDS}

Table 1. Neuroimaging studies in patients with corticobasal degeneration (CBD) and corticobasal syndrome (CBS). PET: positron emission tomography; [18F]FDG-PET: [(18)F]6-fluorodeoxyglucose-PET; SPECT: single-photon emission computed tomography; FP-CIT SPECT: ioflupane-SPECT; D2: dopamine receptor 2; IBZM: iodobenzamide; CBF: cerebral blood flow; MRI: magnetic resonance imaging; GM: gray matter; WM: white matter; VBM: voxel-based morphometry; DTI: diffusion tensor imaging; SBM: surface-

This article is protected by copyright. All rights reserved. 
based morphometry; CTh: cortical thickness; AxD: axial diffusivity; RD: radial diffusivity; Rs-fMRI: resting-state functional-MRI; FC: functional connectivity.

Table 2. Neurophysiological studies in patients with corticobasal syndrome (CBS). SEPs: somatosensory evoked potentials; TMS: transcranial magnetic stimulation; RMT: resting motor threshold; iSP: ipsilateral silent period; cSP: cortical silent period; I/O: input/output; MEP: motor evoked potential; SICI: short-interval intracortical inhibition; ICF: intracortical facilitation; iTBS: intermittent theta burst stimulation; cTBS: continuous theta burst stimulation; LTP: long-term potentiation; LTD: long-term depression.

This article is protected by copyright. All rights reserved. 


\begin{tabular}{|c|c|c|c|c|}
\hline Reference & $\begin{array}{l}\text { Number of } \\
\text { patients }\end{array}$ & $\begin{array}{l}\text { Pathological } \\
\text { diagnosis of } \\
\text { CBD }\end{array}$ & Technique & Main finding \\
\hline $\begin{array}{l}\text { Niethammer et al., } \\
2014\end{array}$ & $10 \mathrm{CBD}$ & No & [18F]FDG-PET & $\begin{array}{l}\text { Bilateral, } \\
\text { asymmetric metabolic reductions in } \\
\text { frontal and parietal cortex, thalamus, and } \\
\text { caudate nucleus contralateral to the more } \\
\text { affected limb }\end{array}$ \\
\hline Turaga et al., 2013 & $17 \mathrm{CBS}$ & No & [18F]FDG-PET & $\begin{array}{l}\text { Asymmetric focal hypometabolism in } \\
\text { frontal, parietal, temporal lobes and } \\
\text { basal ganglia }\end{array}$ \\
\hline Blin et al., 1992 & $5 \mathrm{CBS}$ & No & [18F]FDG-PET & $\begin{array}{l}\text { Asymmetric metabolic reductions in the } \\
\text { temporal and sensorimotor cortex and } \\
\text { thalamus contralateral to the most } \\
\text { affected limbs }\end{array}$ \\
\hline $\begin{array}{l}\text { Eidelberg et al., } \\
1991\end{array}$ & $5 \mathrm{CBD}$ & No & [18F]FDG-PET & $\begin{array}{l}\text { Asymmetric reduction of metabolism in } \\
\text { the frontal and parietal lobe and, } \\
\text { thalamus }\end{array}$ \\
\hline $\begin{array}{l}\text { Kaasinen et al., } \\
2013\end{array}$ & $1 \mathrm{CBD}$ & Yes & FP-CIT.SPECT & $\begin{array}{l}\text { Preserved presynaptic dopaminergic } \\
\text { bindings }\end{array}$ \\
\hline Ceravolo et al., 2013 & $4 \mathrm{CBS}$ & No & FP-CIT.SPECT & $\begin{array}{l}\text { Pathological presynaptic dopaminergic } \\
\text { uptake performed } 10-15 \text { months apart } \\
\text { from the baseline scan. }\end{array}$ \\
\hline Cilia et al., 2011 & $36 \mathrm{CBS}$ & No & FP-CIT-SPECT & $\begin{array}{l}\text { Large variability in presynaptic } \\
\text { dopaminergic bindings. No correlation } \\
\text { between tracer uptake values and clinical } \\
\text { features }\end{array}$ \\
\hline $\begin{array}{l}\text { O'Sullivan et al., } \\
2008\end{array}$ & $1 \mathrm{CBD}$ & Yes & FP-CIT-SPECT & $\begin{array}{l}\text { Preserved presynaptic dopaminergic } \\
\text { bindings }\end{array}$ \\
\hline Pirker et al., 2013 & $9 \mathrm{CBS}$ & $\begin{array}{l}\text { Only in } 2 \\
\text { patients }\end{array}$ & $\begin{array}{l}\text { D2 receptor-SPECT- } \\
\text { (123)I-IBZM }\end{array}$ & $\begin{array}{l}\text { Preserved striatal D2 receptor binding } \\
\text { but more asymmetric than in controls }\end{array}$ \\
\hline Frisoni et al., 1995 & $1 \mathrm{CBS}$ & No & $\begin{array}{l}\text { D2 receptor-SPECT- } \\
\text { (123)I-IBZM }\end{array}$ & $\begin{array}{l}\text { Reduced and asymmetric striatal D2 } \\
\text { receptor binding }\end{array}$ \\
\hline Klaffke et al., 2006 & $8 \mathrm{CBS}$ & No & $\begin{array}{l}\text { D2 receptor-SPECT- } \\
(123) \text { I- } \\
\text { IBZM/[18F]FDG }\end{array}$ & $\begin{array}{l}\text { Contralateral hypometabolism in cortical } \\
\text { and subcortical areas. Decreased } \\
\text { presynaptic dopamine transporter } \\
\text { binding. Preserved D2 receptor }\end{array}$ \\
\hline $\begin{array}{l}\text { Hammesfahr et al., } \\
2016\end{array}$ & $23 \mathrm{CBS}$ & No & $\begin{array}{l}\text { FP-CIT-SPECT and D2 } \\
\text { receptor-SPECT- } \\
(123) \text { I-IBZM }\end{array}$ & $\begin{array}{l}\text { Asymmetric reduction in presynaptic } \\
\text { dopaminergic binding. IBZM uptake did } \\
\text { not show abnormalities }\end{array}$ \\
\hline Plotkin et al., 2005 & $9 \mathrm{CBS}$ & No & $\begin{array}{l}\text { FP-CIT-SPECT and D2 } \\
\text { receptor-SPECT- } \\
(123) \text { I-IBZM }\end{array}$ & $\begin{array}{l}\text { Reduction in presynaptic dopaminergic } \\
\text { binding contralateral to the more } \\
\text { affected side. Reduced D2 receptor in } \\
2 / 9 \text { CBS patietns }\end{array}$ \\
\hline Abe et al., 2016 & $26 \mathrm{CBS}$ & No & MRI and CBF-SPECT & $\begin{array}{l}\text { Left frontal and temporal atrophy in } \\
\text { CBS with aphasia. The CBF in the left } \\
\text { middle frontal gyrus differed between } \\
\text { CBS patients with and without aphasia }\end{array}$ \\
\hline
\end{tabular}

This article is protected by copyright. All rights reserved. 


\begin{tabular}{|c|c|c|c|c|}
\hline Slawek et al., 2001 & $2 \mathrm{CBD}$ & No & CBF-SPECT & $\begin{array}{l}\text { left fronto-parieto-temporal cortex and } \\
\text { striatal hypoperfusion }\end{array}$ \\
\hline Markus et al., 1995 & $8 \mathrm{CBS}$ & No & CBF-SPECT & $\begin{array}{l}\text { Hypoperfusion in the frontal and parietal } \\
\text { cortex contralateral to the more affected } \\
\text { arm }\end{array}$ \\
\hline Hirano et al., 2010 & 7 CBS & No & $\begin{array}{l}{[11 \mathrm{C}] \mathrm{N}-} \\
\text { methylpiperidin-4-yl } \\
\text { acetate-PET }\end{array}$ & $\begin{array}{l}\text { Altered cholinergic transmission in the } \\
\text { paracentral region, frontal, parietal and } \\
\text { occipital cortices }\end{array}$ \\
\hline $\begin{array}{l}\text { Nagasawa et al., } \\
1996\end{array}$ & $6 \mathrm{CBS}$ & No & $\begin{array}{l}{[18 \mathrm{~F}] \mathrm{FDG}} \\
\text { and[18F]dopa-PET }\end{array}$ & $\begin{array}{l}\text { Asymmetric reduction of glucose } \\
\text { metabolism in frontal and parietal cortex } \\
\text { and basal ganglia. Asymmetric reduction } \\
\text { of [18F]dopa in basal ganglia }\end{array}$ \\
\hline Cho et al., 2017 & $6 \mathrm{CBS}$ & No & $\begin{array}{l}{[18 \mathrm{~F}]-\mathrm{AV}-1451-\mathrm{PET}} \\
\text { (tau) }\end{array}$ & $\begin{array}{l}\text { Asymmetric increase of } 18 \mathrm{~F}-\mathrm{AV}-1451 \\
\text { binding in the putamen, globus pallidus, } \\
\text { and thalamus contralateral to the } \\
\text { clinically more affected side }\end{array}$ \\
\hline Smith et al., 2017 & $8 \mathrm{CBS}$ & No & $\begin{array}{l}{[18 \mathrm{~F}]-\mathrm{AV}-1451-\mathrm{PET}} \\
\text { (tau) }\end{array}$ & $\begin{array}{l}\text { Increased signal in the motor cortex, } \\
\text { corticospinal tract, and basal ganglia } \\
\text { contralateral to the affected body side }\end{array}$ \\
\hline Josephs et al., 2016 & $1 \mathrm{CBD}$ & Yes & $\begin{array}{l}{[18 \mathrm{~F}]-\mathrm{AV}-1451-\mathrm{PET}} \\
\text { (tau) }\end{array}$ & $\begin{array}{l}\text { Increased signal in putamen, pallidum, } \\
\text { thalamus, precentral cortex, rolandic } \\
\text { operculum, supplemental motor area, } \\
\text { and left Broca's area }\end{array}$ \\
\hline $\begin{array}{l}\text { McMillan et al., } \\
2016\end{array}$ & $1 \mathrm{CBD}$ & Yes & $\begin{array}{l}{[18 \mathrm{~F}]-\mathrm{AV}-1451-\mathrm{PET}} \\
\text { (tau) }\end{array}$ & $\begin{array}{l}\text { Increased signal in substantia nigra, } \\
\text { globus pallidus, midbrain, bilateral } \\
\text { frontal, posterior temporal cortex }\end{array}$ \\
\hline Kikuchi et al., 2016 & $5 \mathrm{CBS}$ & $\begin{array}{l}\text { Only in a single } \\
\text { patient }\end{array}$ & 18F-THK5351 & $\begin{array}{l}\text { Higher 18F-THK5351 retention in the } \\
\text { frontal, parietal, and globus pallidus, } \\
\text { contralaterally to the side associated } \\
\text { with greater cortical dysfunction and } \\
\text { parkinsonism. }\end{array}$ \\
\hline Josephs et al., 2004 & $6 \mathrm{CBD}$ & Yes & MRI & $\begin{array}{l}\text { Fronto-parietal cortical and middle } \\
\text { corpus callosum atrophy }\end{array}$ \\
\hline Solivieri et al., 1999 & $16 \mathrm{CBS}$ & No & MRI & $\begin{array}{l}\text { Asymmetric fronto-parietal cortical } \\
\text { atrophy }\end{array}$ \\
\hline Hauser et al., 1996 & $8 \mathrm{CBS}$ & No & MRI & $\begin{array}{l}\text { Asymmetrical cortical atrophy } \\
\text { contralateral to the more affected side }\end{array}$ \\
\hline Grisoli et al., 1995 & $10 \mathrm{CBS}$ & No & MRI & $\begin{array}{l}\text { Asymmetric atrophy (posterior-frontal } \\
\text { and parietal regions) contralateral to the } \\
\text { more affected side }\end{array}$ \\
\hline Gröschel et al., 2004 & $18 \mathrm{CBS}$ & No & MRI volumetric & $\begin{array}{l}\text { GM loss in mid-brain, parietal WM, } \\
\text { brainstem, pons, temporal brain regions }\end{array}$ \\
\hline Yu et al., 2015 & $\begin{array}{l}165 \text { CBS (meta- } \\
\text { analysis study) }\end{array}$ & No & MRI (VBM) & $\begin{array}{l}\text { Asymmetric gray matter atrophy in } \\
\text { multiple cortical regions mainly } \\
\text { involving the superior parietal lobe }\end{array}$ \\
\hline Burrell et al., 2014 & $17 \mathrm{CBS}$ & No & MRI (VBM) & $\begin{array}{l}\text { 10/17 patients with asymmetric atrophy } \\
\text { of the primary motor and pre- }\end{array}$ \\
\hline
\end{tabular}

This article is protected by copyright. All rights reserved. 


\begin{tabular}{|c|c|c|c|c|}
\hline & & & & $\begin{array}{l}\text { motor cortices and thalamus. } \\
\text { Apraxia correlates with pre-motor and } \\
\text { parietal atrophy }\end{array}$ \\
\hline Jutten et al., 2014 & $\begin{array}{l}8 \mathrm{CBS} \text { (left vs } \\
\text { right affected } \\
\text { side) }\end{array}$ & No & MRI (VBM) & $\begin{array}{l}\text { Asymmetric primary motor areas } \\
\text { atrophy in the hemisphere contralateral } \\
\text { to the apraxic limb. Volumetric grey } \\
\text { matter loss related to CBS pathology } \\
\text { appears and progresses faster in l-CBS } \\
\text { than in r-CBS }\end{array}$ \\
\hline Whitwell et al., 2010 & $7 \mathrm{CBD}$ & Yes & MRI (VBM) & $\begin{array}{l}\text { Focal atrophy involving the premotor } \\
\text { and supplemental motor area }\end{array}$ \\
\hline Josephs et al., 2008 & $21 \mathrm{CBD}$ & Yes & MRI (VBM) & $\begin{array}{l}\text { Asymmetric frontoparietal grey and } \\
\text { subcortical grey matter atrophy (visual } \\
\text { assessment) }\end{array}$ \\
\hline Boxer et al., 2006 & $14 \mathrm{CBS}$ & No & MRI (VBM) & $\begin{array}{l}\text { Asymmetric pattern of brain atrophy in } \\
\text { premotor and parietal cortex, superior } \\
\text { parietal lobules, and striatum }\end{array}$ \\
\hline Borroni et al., 2008 & $20 \mathrm{CBS}$ & Yes & MRI (VBM) and DTI & $\begin{array}{l}\text { Limb apraxia correlates with parietal } \\
\text { atrophy and with fractional anisotropy } \\
\text { reductions in the parietofrontal } \\
\text { associative fibers }\end{array}$ \\
\hline $\begin{array}{l}\text { Upadhyay et al., } \\
\text { 2016a }\end{array}$ & $11 \mathrm{CBS}$ & No & SBM and DTI & $\begin{array}{l}\text { Reduced CTh in the fronto-parietal } \\
\text { regions contralateral to the clinically } \\
\text { more affected side. AxD more affected } \\
\text { than RD }\end{array}$ \\
\hline $\begin{array}{l}\text { Upadhyay et al., } \\
2016 b\end{array}$ & $11 \mathrm{CBS}$ & No & SBM and DTI & $\begin{array}{l}\text { Reduced CTh in peri-rolandic brain } \\
\text { regions }\end{array}$ \\
\hline Zhang et al., 2016 & $25 \mathrm{CBS}$ & No & DTI & $\begin{array}{l}\text { Anisotropy reduction around the central } \\
\text { sulci, and diffusivity increase in the } \\
\text { superior fronto-occipital fascicules }\end{array}$ \\
\hline $\begin{array}{l}\text { Tovar-Moll et al., } \\
2014\end{array}$ & $19 \mathrm{CBS}$ & No & DTI & $\begin{array}{l}\text { Damage to the midbody of the corpus } \\
\text { callosum and perirolandic corona radiata }\end{array}$ \\
\hline Whitwell et al., 2014 & $9 \mathrm{CBS}$ & No & DTI & $\begin{array}{l}\text { Asymmetric degeneration of the } \\
\text { splenium of the corpus callosum, } \\
\text { premotor and prefrontal white matter } \\
\text { lobes }\end{array}$ \\
\hline $\begin{array}{l}\text { Upadhyay et al., } \\
2017\end{array}$ & $11 \mathrm{CBS}$ & No & Rs-fMRI & $\begin{array}{l}\text { Increased FC between the dentate } \\
\text { nucleus and the sensorimotor cortices } \\
\text { contralateral to the most clinically } \\
\text { affected body side }\end{array}$ \\
\hline Bharti et al., 2017 & $11 \mathrm{CBS}$ & No & Rs-fMRI & $\begin{array}{l}\text { Increased within-network FC in the } \\
\text { cerebellum, sensorimotor, executive- } \\
\text { control and insular networks. }\end{array}$ \\
\hline Ukmar et al., 2003 & $7 \mathrm{CBS}$ & No & Rs-fMRI & $\begin{array}{l}\text { Decreased activation of the parietal lobe } \\
\text { contralateral to the more affected arm }\end{array}$ \\
\hline
\end{tabular}

This article is protected by copyright. All rights reserved. 


\begin{tabular}{|c|c|c|c|c|}
\hline Reference & $\begin{array}{l}\text { Number of } \\
\text { patients }\end{array}$ & $\begin{array}{l}\text { Pathological } \\
\text { diagnosis of } \\
\text { CBD }\end{array}$ & Technique & Main Finding \\
\hline Okuda et al., 1998 & $5 \mathrm{CBS}$ & No & SEPs & Prolonged N20 latencies (apraxic limb) \\
\hline Brunt et al., 1995 & $2 \mathrm{CBS}$ & No & SEPs & $\begin{array}{l}\text { Small N20-P25, No giant SEPs (limb with } \\
\text { myoclonus) }\end{array}$ \\
\hline $\begin{array}{l}\text { Leiguarda et al., } \\
2003\end{array}$ & $5 \mathrm{CBS}$ & No & $\begin{array}{l}\text { movement } \\
\text { analysis }\end{array}$ & $\begin{array}{l}\text { Delayed initiation, distorted and fragmented } \\
\text { finger movements }\end{array}$ \\
\hline Pal et al., 2008 & $7 \mathrm{CBS}$ & No & single pulse TMS & $\begin{array}{l}\text { Normal/incr. RMT, reduced iSP, normal } \\
\text { cSP and I/O }\end{array}$ \\
\hline Kühn et al., 2004 & $13 \mathrm{CBS}$ & No & single pulse TMS & $\begin{array}{l}\text { Reduced RMT, MEP amplitude, I/O, cSP } \\
\text { and iSP }\end{array}$ \\
\hline $\begin{array}{l}\text { Trompetto et al., } \\
2003\end{array}$ & $7 \mathrm{CBS}$ & No & single pulse TMS & Reduced iSP duration \\
\hline $\begin{array}{l}\text { Leiguarda et al., } \\
2003\end{array}$ & $5 \mathrm{CBS}$ & No & single pulse TMS & Reduced cSP (apraxic limb) \\
\hline $\begin{array}{l}\text { Valls-Solé et al., } \\
2001\end{array}$ & $10 \mathrm{CBS}$ & No & single pulse TMS & $\begin{array}{l}\text { Increased RMT, reduced MEP amplitude } \\
\text { and cSP }\end{array}$ \\
\hline Lu et al., 1998 & $2 \mathrm{CBS}$ & No & single pulse TMS & $\begin{array}{l}\text { Increased RMT, reduced MEP amplitude } \\
\text { and cSP }\end{array}$ \\
\hline Pal et al., 2008 & $7 \mathrm{CBS}$ & No & paired pulse TMS & Reduced SICI, normal ICF \\
\hline Kühn et al., 2004 & $13 \mathrm{CBS}$ & No & paired pulse TMS & Reduced SICI, normal ICF \\
\hline Okuma et al., 2000 & 4 CBS & No & paired pulse TMS & Reduced SICI \\
\hline $\begin{array}{l}\text { Hanajima et al., } \\
1996\end{array}$ & $1 \mathrm{CBS}$ & No & paired pulse TMS & Reduced SICI \\
\hline Suppa et al., 2016a & $17 \mathrm{CBS}$ & No & iTBS/cTBS & $\begin{array}{l}\text { Reduced LTP/LTD-like plasticity } \\
\text { (park.hemisphere) } \\
\text { red. or incr. LTP/LTD-like plasticity } \\
\text { (park.plus hemisphere) }\end{array}$ \\
\hline
\end{tabular}

This article is protected by copyright. All rights reserved. 

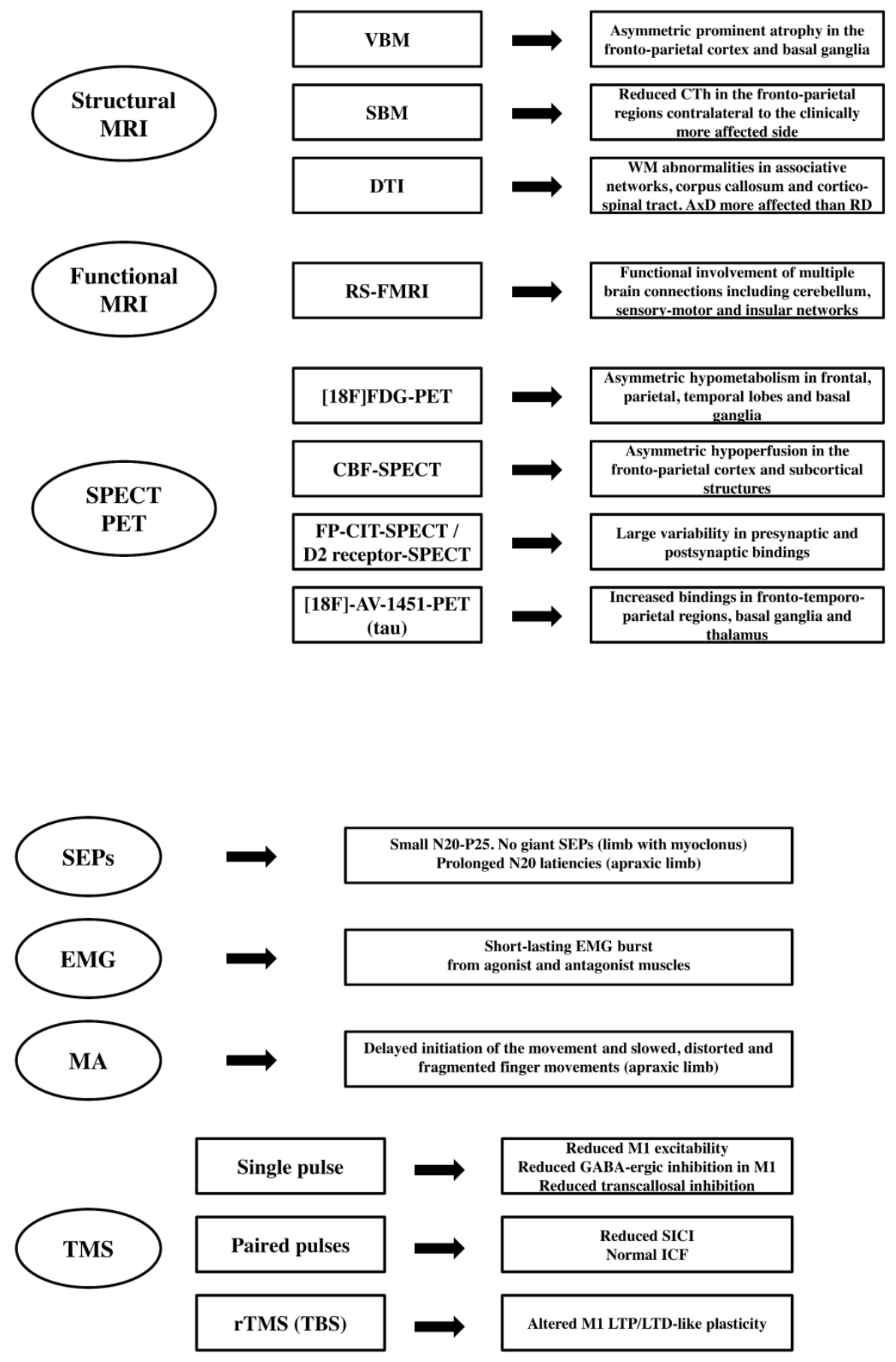

This article is protected by copyright. All rights reserved. 